\title{
THE MASSES OF THE PRINCIPAL PLANETS
}

\author{
W. J. KLEPCZYNSKI, P. K. SEIDELMANN, and R. L. DUNCOMBE \\ U.S. Naval Observatory, Washington, U.S.A.
}

\author{
(Presented at IAU Colloquium No. 9, 'The IAU System of \\ Astronomical Constants', Heidelberg, Germany, August 12-14, 1970.)
}

\begin{abstract}
A set of masses for the principal planets is derived systematically from all available fundamental and independent determinations. In deriving these values an attempt has been made to treat independently those determinations based on differing observational types or analytical methods.
\end{abstract}

\section{Introduction}

The planetary masses currently incorporated in the national ephemerides are essentially those deduced by Newcomb (1898a, 1898b). More recently, compilations have been made by Kozlovskaya (1963), Clemence (1964) and Kulikov (1965). Brouwer and Clemence (1961) review past determinations, and also discuss the several methods by which planetary masses can be deduced.

The determination of the mass of a planet, whether derived from its periodic perturbations of an adjacent body, from its effect on the secular motions of other planets, or from measures of the motion of its satellites, may be affected by systematic errors the extent of which are not reflected in the formal mean error given by the investigator. Attempts to evaluate the systematic errors present in the data were nonconclusive, so, while the presence of systematic effects is suspected, there is no known method of correcting for the unknown effect.

In the present study, the various independent determinations of the planetary masses are segregated by observation type and analytical method to form group means. The group means are examined to see if they form an accordant or discordant data set. The group means are then combined to form the final value.

In Tables I through IX are assembled in chronological order all of the published determinations of the masses of the principal planets known to us. Those results which in our judgment are fundamental and independent have been analyzed in groups depending on observation type and analytical method; that is those determinations depending principally on radar measures have been placed together; those resulting from satellite measures are grouped, etc. For each planet the determinations that have been superseded by later investigations utilizing the same data and the same method were omitted from consideration. If previously used data were analyzed again by a significantly different method, the determination was considered independent.

\section{Formation of Group Means and Their Errors}

The group means were formed by a weighted mean of the closely related but not redundant determinations, the weighting factors being determined usually by the 
mean error associated with each value. Where a multitude of measures are available a method of elimination similar to Taylor et al. (1969) can be used, where any datum with an error greater than three times that of a similar datum is discarded. In the case of the planetary masses, there are not sufficient data.

There are two methods to determine the mean error of a weighted mean. The first method bases the mean error $(e)$ of the weighted mean on the mutual discordances of the individual items with respect to the mean:

$$
e=\sqrt{\frac{\sum w_{i} r_{i}^{2}}{(n-1) \sum w_{i}}}
$$

where $w_{i}$ is the weight of the $i$ th item, $r_{i}$ is the residual of the $i$ th item with respect to the mean and $n$ is the number of individual items entering the mean.

The second method considers the weighted mean to be a simple linear combination of several items and consequently considers the mean error of the mean to be a linear combination of the corresponding mean errors of the individual items. The resulting expression for the mean error of the weighted mean is

$$
e^{\prime}=\sqrt{\frac{e_{0}^{2}}{\sum w_{i}}}
$$

where $w_{i}$ is the weight determined from $w_{i}=e_{0}^{2} / e_{i}^{2}, e_{i}$ is the mean error of an individual determination, and $e_{0}$ is an arbitrary, but consistent, quantity. In each case $e_{0}$ was selected as the largest mean error entering the group mean, so the smallest weight was unity.

Both methods suffer from the fact that they do not always give a true indication of the mean error of the mean. For the first method (e), consider the case when a mean value is formed from two items which are very close together, but each having large mean errors associated with them. Since the deviations from the mean are small, the resulting mean error will be small, but it will not reflect the large mean errors of the individual determinations.

In the second method $\left(e^{\prime}\right)$, examine the case when a mean value is formed from two items which are separated by a considerable amount, but each having small mean errors associated with them. Since the mean errors are small, the mean error of the mean value will be small, and the deviation of the values making up the mean will not be reflected in the resulting mean error.

In this investigation, due to the paucity of mass determinations, very few items are being combined to form a mean value. The character of these data is carefully examined before choosing the method to form the mean error of the weighted mean.

After forming a weighted group mean, it is frequently the practice in statistics to discard determinations exceeding three or more times the standard deviation of unit weight $(\sigma)$ as determined by

$$
\sigma=\sqrt{\frac{\sum w_{i} r_{i}^{2}}{(n-1)}} .
$$


When a large variation of weights occurs, the value of sigma resulting is dependent on the system of weights used and is not a valid basis for rejecting independent determinations. In this investigation, no independent determinations have been rejected solely on the magnitude of their residuals.

\section{Formation of Final Values}

On inspecting the various group means for each planet, it was apparent that the values could be considered as fairly accordant sets of data. It was therefore decided to calculate the final mean value for each planet by forming a weighted mean of the group means. The final values are considered to comprise not only the mass of the planet, but its satellites and atmosphere, if any. As a check on the consistency of the results, a simple arithmetic mean of the group means was formed for each planet, which in all cases compared reasonably with the weighted mean.

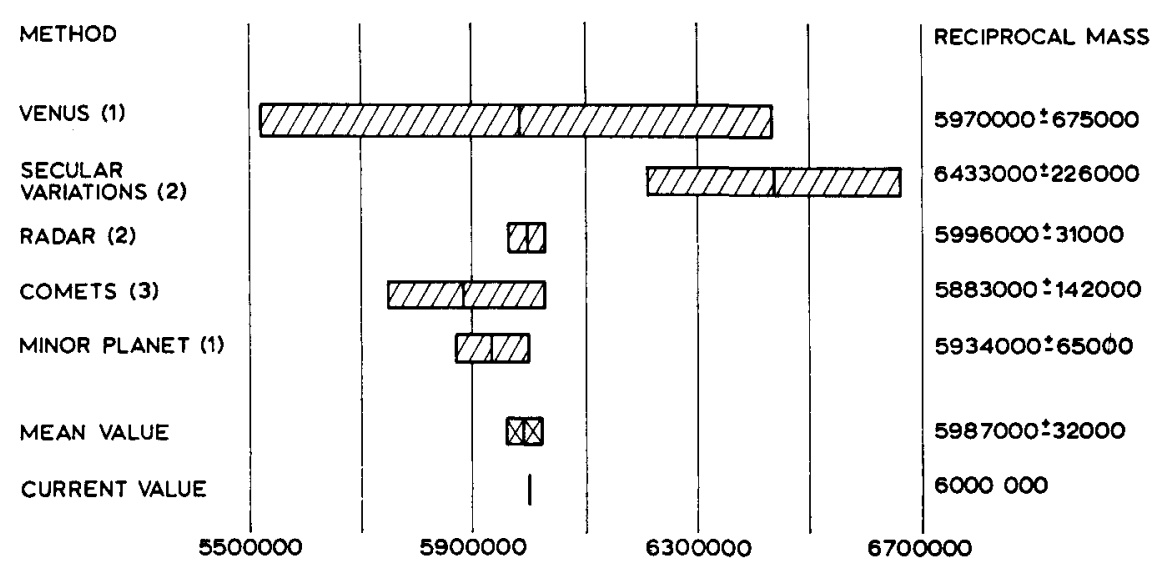

Fig. 1. Reciprocal mass of Mercury.

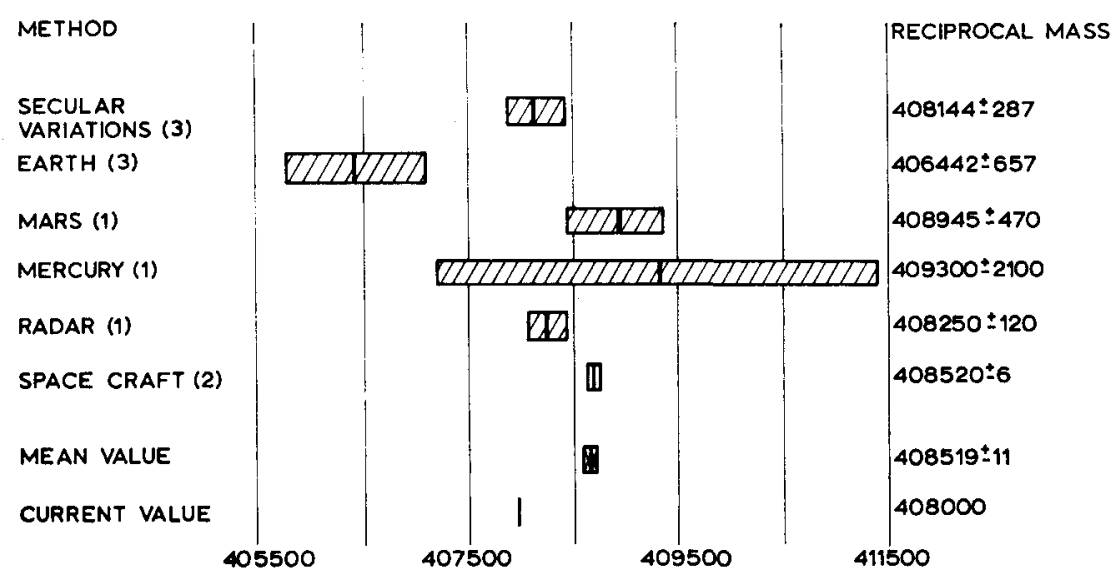

Fig. 2. Reciprocal mass of Venus. 


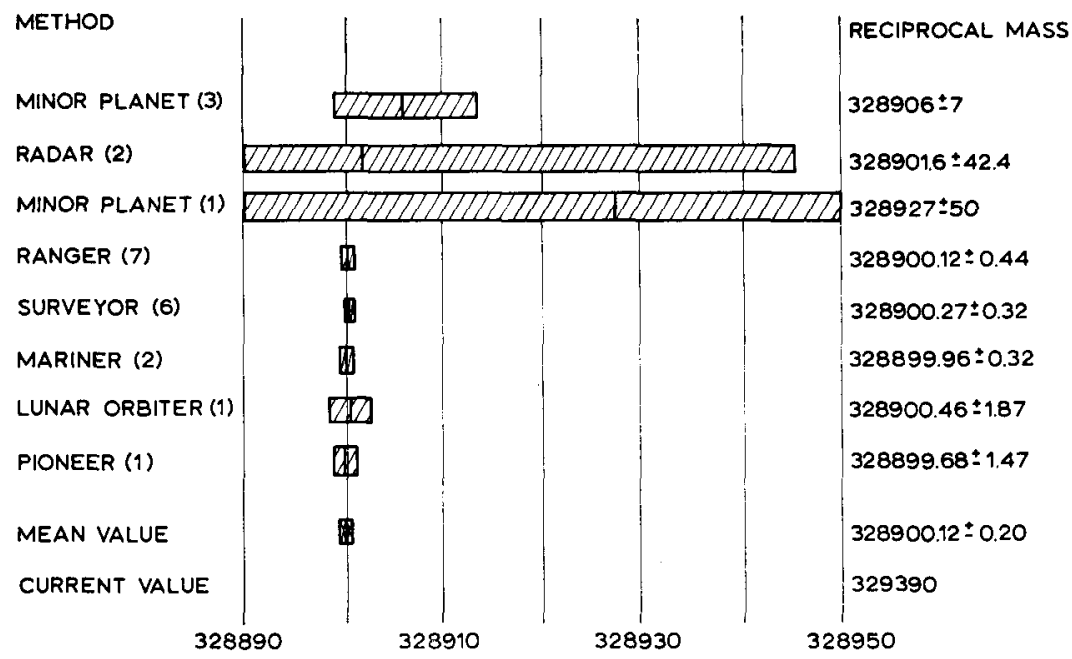

Fig. 3. Reciprocal mass of Earth-Moon.

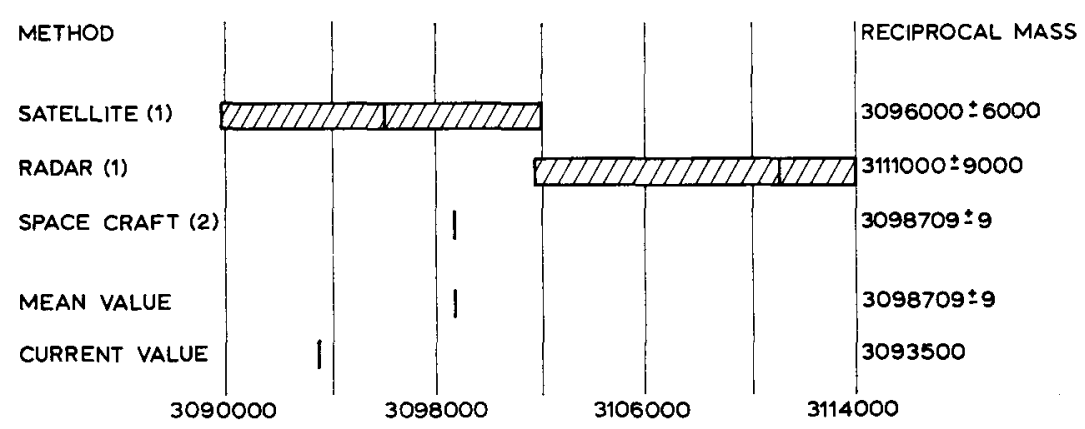

Fig. 4. Reciprocal mass of Mars.

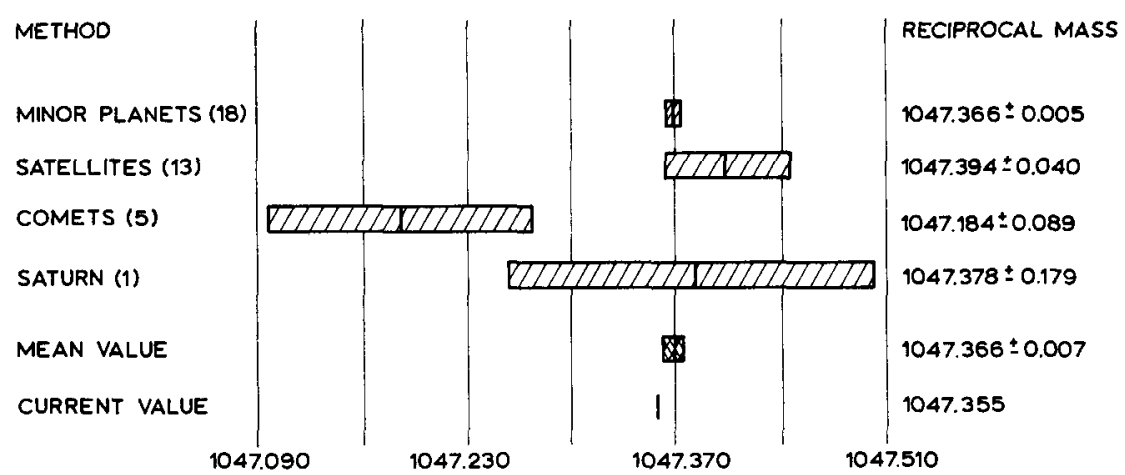

Fig. 5. Reciprocal mass of Jupiter. 

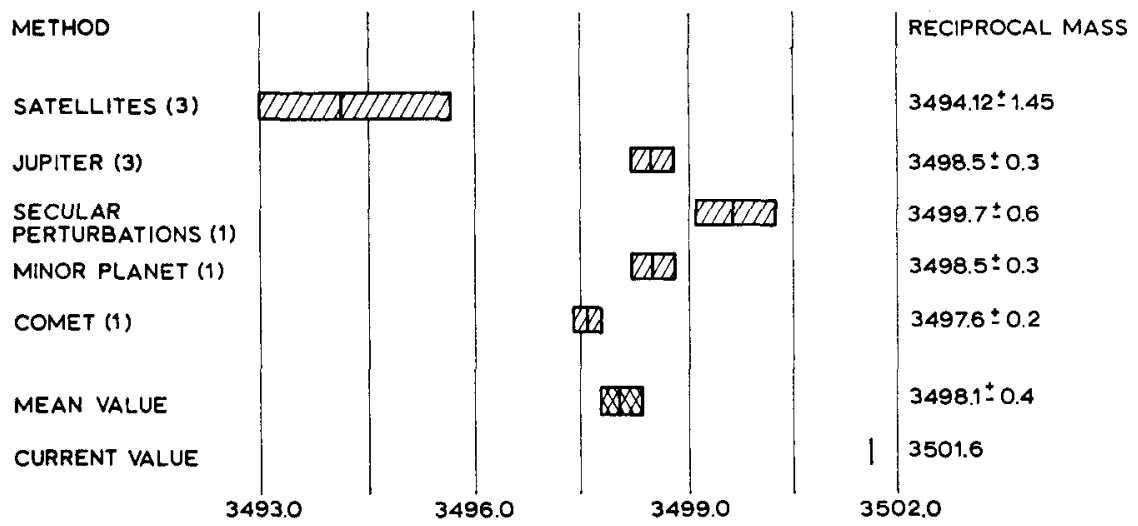

Fig. 6. Reciprocal mass of Saturn.

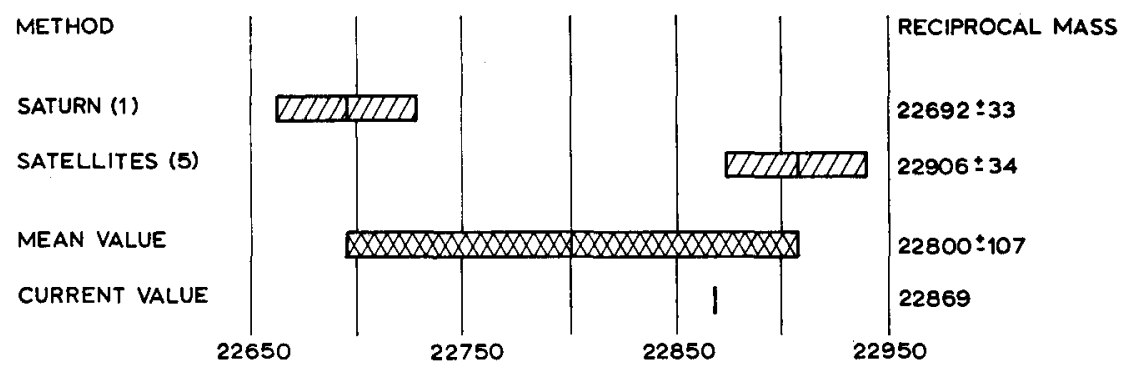

Fig. 7. Reciprocal mass of Uranus.

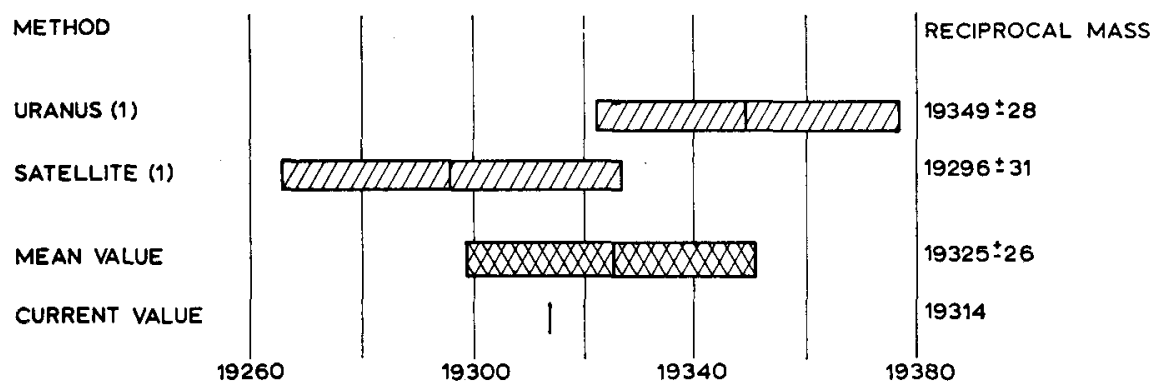

Fig. 8. Reciprocal mass of Neptune.

In Tables I to IX, determinations that enter the final weighted mean individually are marked by an asterisk $\left(^{*}\right)$ while those that are part of a group mean are marked by a cross $(+)$. In addition, the value currently adopted by the IAU and our deduced weighted mean are listed at the bottom of each table. The associated mean errors are those resulting from the solution in all cases except Pluto.

Figures 1 to 8 present graphically the value and its mean error for the group means, the final mean value, and the currently adopted value for each planet. The number in parentheses after the description of the method is the number of independent determinations entering the group mean. 


\section{Mercury, Table I}

(a) The reciprocal mass of Mercury from the periodic perturbations in the motion of Venus determined by Duncombe (1958) supersedes that of Newcomb (1895) and was adopted.

(b) From the analyses of the secular variations of the inner planets, von Haerdtl (1889) is superseded by Clemence (1949) and Brouwer (1950) and a weighted mean of 6433000 for the reciprocal mass of Mercury was determined. While these two values differ only slightly, they each have large mean errors, so the mean error of the group mean $( \pm 226000)$ was based on the given mean errors rather than on the discordance of the determinations.

(c) The values of the reciprocal mass of Mercury based principally on radar range measurements by Ash et al. (1967) and Melbourne (1968) were combined to give a group mean of $5996000 \pm 31000$. This mean error is based on the mean error of the determinations rather than on their residuals from the mean.

(d) The results based on observations of the comets Winnecke by von Haerdtl (1889) and Encke by Backlund (1894) were rejected because of the admittedly poor quality of the observations involved. The determinations based on Encke's Comet by von

TABLE I

Investigations of the mass of Mercury

\begin{tabular}{|c|c|c|c|c|c|}
\hline No. & $\begin{array}{l}\text { Reciprocal } \\
\text { mass }\end{array}$ & Mean error & Author & Year & Object \\
\hline 1 & 5012842 & \pm 1034637 & von Haerdtl & 1889 & Winnecke's comet \\
\hline 2 & 5514700 & \pm 148000 & von Haerdtl & 1889 & Secular perturbations \\
\hline $3+$ & 5648600 & 3000 & von Haertdl & 1889 & Encke comet (1819-68) \\
\hline $4+$ & 5669700 & \pm 890000 & von Haertdl & 1889 & Encke comet (1871-85) \\
\hline 5 & 9700000 & \pm 1000000 & Backlund & 1894 & Encke comet \\
\hline 6 & 7210000 & \pm 2307000 & Newcomb & $1895 \mathrm{~b}$ & Venus $(1750-1892) \alpha$ and $\delta$ \\
\hline 7 & 7943000 & \pm 2780000 & Newcomb & $1895 b$ & Venus $(1750-1892) \alpha$ only \\
\hline $8+$ & 6400000 & \pm 300000 & Clemence & 1949 & $\begin{array}{l}\text { Motion of perihelion of Earth } \\
\text { and Mercury }\end{array}$ \\
\hline 9 & 6120000 & \pm 64000 & Rabe & 1950 & Eros $(1926-45)$ \\
\hline $10+$ & 6480000 & \pm 350000 & Brouwer & 1950 & Secular perturbations \\
\hline 11 & 6280000 & \pm 350000 & Makover & 1956 & Encke comet (1937-54) \\
\hline $12 *$ & 5970000 & \pm 675000 & Duncombe & 1958 & Venus (1750-1949) \\
\hline $13+$ & 5980000 & \pm 170000 & $\begin{array}{l}\text { Makover and } \\
\text { Bokhan }\end{array}$ & 1961 & Encke comet (1898-1954) \\
\hline $14+$ & 6021000 & $\pm \quad 53000$ & Ash et al. & 1967 & $\begin{array}{l}\text { Radar data (1959-66) } \\
\text { Optical data }(1950-65)\end{array}$ \\
\hline $15+$ & 5983000 & $\pm \quad 37000$ & $\begin{array}{l}\text { Melbourne, } \\
\text { O'Handley and } \\
\text { Reed (see } \\
\text { Melbourne et al., } \\
\text { 1968) }\end{array}$ & 1968 & Venus radar observations \\
\hline $16 *$ & $\begin{array}{l}5934000 \\
6000000 \\
5987000\end{array}$ & $\begin{array}{l} \pm \quad 65000 \\
\pm \quad 32000\end{array}$ & $\begin{array}{l}\text { Lieske and Null } \\
\text { Currently adopted } \\
\text { Weighted mean }\end{array}$ & 1969 & Icarus \\
\hline
\end{tabular}


Haerdtl (1889) from observations over the period 1819-1868, by von Haerdtl (1889) from observations 1871-1885, and by Makover and Bokhan (1961) from observations 1898-1954, which supersedes Makover (1956), are combined with relative weights of 15,8 and 54 respectively. These weights are the product of the number of oppositions of the comet in each observational period, 15, 4 and 18 respectively, times a quality factor 1, 2 or 3, based on the epoch of the observations. This method of weighting was used because the published mean errors have a questionably large variation in magnitude. The resulting group mean for the reciprocal mass of Mercury was $5883000 \pm$ \pm 142000 where the mean error is derived from the published mean errors and assigned weights.

(e) The analysis of perturbations induced in the motion of minor planet Icarus by Lieske and Null (1969) was adopted. The mass derived from Eros by Rabe (1950) is omitted because subsequent analysis of the observations by Rabe (1967) indicates the value is poorly determined. The values of the mass of Venus, the Earth-Moon, and Mars resulting from the same investigation are also omitted.

In forming the weighted mean the group means were given weights of $1,9,474,23$, and 108 respectively. The resultant reciprocal mass of Mercury is $5987000 \pm 32000$ where the mean error is based on the residuals from the mean value.

\section{Venus, Table II}

(a) The reciprocal masses of Venus determined from secular perturbations by Fotheringham (1935), Clemence (1949) and Brouwer (1950) were combined to give a weighted group mean of $408144 \pm 287$. The mean error is based on the mean errors of the independent determinations.

(b) While there is some overlapping of observational data, the determinations of the reciprocal mass of Venus derived from periodic perturbations in the motion of the Earth by Newcomb (1898), Jones (1926) and Morgan and Scott (1939) were combined in a group mean to give $406442 \pm 657$. The mean error quoted is based on the discordance among the determinations. The determination by Cowell (1906) is superseded by the other determinations.

(c) Based on the periodic perturbations induced in the motion of Mars, the reciprocal mass of Venus derived by Duncombe (1964), which supersedes Ross (1917) and Jones (1925 and 1927) is adopted.

(d) The reciprocal mass determined from periodic perturbations in the motion of Mercury by Clemence (1943), which supersedes Newcomb (1898) and Williams (1939), is adopted.

(e) The reciprocal mass of Venus derived by Ash et al. (1967) from a solution incorporating both radar and optical observations is adopted.

(f) The value of the reciprocal mass of Venus deduced from perturbations in the motion of the spacecraft Mariner 2 by Anderson (1967) and the spacecraft Mariner 5 by Anderson et al. (1968) were combined to give a weighted group mean of $408520 \pm 6$. The mean error is determined from the discordance between the two values. 
Several investigators have derived new values for the masses of Venus and Mercury on the hypothesis that errors in these masses are the sole cause of the difference between the observed and theoretical secular variation of the obliquity of the ecliptic. Morgan (1933) deduced a reciprocal mass of Venus of 405560 and Jones (1932) determined values of 403030 and 405800 . Jones (1932) also derived a reciprocal mass of Mercury of 7000000. Since other independent information does not support this hypothesis, these mass values are omitted from the discussion.

In determining the final weighted mean, the group means received weights of 54,10 , $20,1,306$, and 122500 , respectively. The resulting value is $408519 \pm 11$ where the mean error is based on the discordance of the group means.

TABLE II

Investigations of the mass of Venus

\begin{tabular}{|c|c|c|c|c|c|}
\hline No. & $\begin{array}{l}\text { Reciprocal } \\
\text { mass }\end{array}$ & Mean error & Author & Year & Object \\
\hline $1+$ & 406650 & \pm 1400 & Newcomb & $1895 b$ & Sun $(1750-1889)$ \\
\hline 2 & 406770 & \pm 2070 & Newcomb & $1895 \mathrm{~b}$ & Mercury (1765-1889) \\
\hline 3 & 399000 & & Cowell & 1906 & Sun $(1864-1900)$ \\
\hline 4 & 403490 & \pm 3600 & Ross & 1917 & Mars (1753-1912) \\
\hline $5+$ & 412700 & \pm 2000 & Jones & 1925 & Mars (1899-1924) \\
\hline 6 & 404700 & \pm 1200 & Jones & 1926 & Sun $(1836-1923)$ \\
\hline 7 & 411300 & \pm 1400 & Jones & 1927 & Mars (1899-1924) \\
\hline $8+$ & 408400 & \pm 2800 & Fotheringham & 1935 & $\begin{array}{l}\text { Perturbations of the obliquity of } \\
\text { the Ecliptic, Sun (1884-1932) }\end{array}$ \\
\hline 9 & 406400 & & Williams & 1939 & Transits of Mercury (1799-1927) \\
\hline $10+$ & 407000 & \pm 700 & Morgan and Scott & 1939 & Sun $(1900-37)$ \\
\hline $11 *$ & 409300 & \pm 2100 & Clemence & 1943 & Mercury (1765-1937) \\
\hline $12+$ & 408150 & \pm 296 & Clemence & 1949 & $\begin{array}{l}\text { From motion of perihelia of } \\
\text { Earth and Mercury }\end{array}$ \\
\hline 13 & 408645 & \pm 308 & Rabe & 1950 & Eros $(1926-45)$ \\
\hline $14+$ & 408000 & \pm 1200 & Brouwer & 1950 & Secular perturbations \\
\hline $15 *$ & 408945 & \pm 470 & $\begin{array}{l}\text { Duncombe } \\
\text { (see IAU Trans.) }\end{array}$ & 1964 & Mars (1750-1955) \\
\hline 16 & 408533.5 & \pm 44 & Anderson et al. & 1964 & Mariner 2, 1962 \\
\hline 17 & 408532 & $\pm \quad 37$ & Anderson & 1964 & Mariner 2 \\
\hline $18+$ & 408507.7 & \pm 7 & Anderson & 1967 & Mariner 2 \\
\hline $19 *$ & 408250 & \pm 120 & Ash et al. & 1967 & $\begin{array}{l}\text { Radar data }(1959-66) \\
\text { Optical data }(1950-65)\end{array}$ \\
\hline $20+$ & $\begin{array}{l}408522 \\
408000\end{array}$ & & $\begin{array}{l}\text { Anderson } \text { et al. } \\
\text { Currently adopted }\end{array}$ & 1968 & Mariner 5 \\
\hline & 408519 & \pm 11 & Weighted mean & & \\
\hline
\end{tabular}

\section{Earth-Moon, Table III}

(a) Based on the perturbations of the motion of Eros, the determinations of the reciprocal mass of the Earth-Moon by Rabe and Francis (1967), Schubart and Zech (1967) and Lieske (1968) supersede the previous work. The seven parameter solution by Rabe and Francis was selected rather than the sixteen parameter solution because 
TABLE III

Investigations of the mass of Earth-Moon

\begin{tabular}{llll}
\hline No. & Reciprocal Mean error Author \\
mass
\end{tabular}

\begin{tabular}{|c|c|c|c|c|c|}
\hline 1 & 329097 & & von Haerdtl & $1889 \mathrm{~b}$ & Winnecke comet \\
\hline 2 & 328016 & & Newcomb & $1895 b$ & Solar parallax \\
\hline 3 & 328882 & \pm 1462 & Witt & 1905 & Eros $(1893-1903)$ \\
\hline 4 & 328659 & \pm 123 & $\begin{array}{l}\text { Witt } \\
\text { (see Noteboom, (1921) }\end{array}$ & 1908 & Eros (1893-1907) \\
\hline 5 & 327463 & \pm 301 & Hinks & 1909 & $\begin{array}{l}\text { Eros }(1900-01) \\
\text { Photo. } \alpha \text { by Trig. }\end{array}$ \\
\hline 6 & 327575 & \pm 446 & Hinks & 1910 & $\begin{array}{l}\text { Eros }(1900-01) \\
\text { Micrometer } \alpha \text { by Trig. }\end{array}$ \\
\hline 7 & 328370 & \pm 102 & Noteboom & 1921 & Eros (1893-1914) \\
\hline 8 & 327950 & \pm 297 & van den Bosch & 1927 & $\begin{array}{l}\text { Combination of parallaxes and } \\
\text { minor planets }\end{array}$ \\
\hline 9 & 328390 & \pm 103 & Witt & 1933 & Eros $(1893-1931)$ \\
\hline 10 & 329367 & \pm 169 & Jones & 1941 & Solar parallax (1930-1) \\
\hline 11 & 328452 & \pm 64 & Rabe & 1950 & Eros \\
\hline 12 & 328446 & \pm 64 & Rabe & 1954 & Eros $(1926-45)$ \\
\hline 13 & 328560 & \pm 133 & Sky and Telescope & 1960 & Pioneer 5 \\
\hline 14 & 328910 & \pm 74 & See Kotelnikov & 1962 & Venus radar obs. \\
\hline $15+$ & 328903.2 & & Muhleman & 1965 & Radar (1961-3) \\
\hline 16 & 328631 & \pm 133 & Rabe & 1967 & Eros (1926-45) 16 parameters \\
\hline 17 & 328875 & \pm 31 & Rabe & 1967 & Eros $(1926-45) 7$ parameters \\
\hline 18 & 328939 & $\pm \quad 40$ & Rabe and Francis & 1967 & Eros $(1926-65) 16$ parameters \\
\hline $19+$ & 328899 & \pm 15 & Rabe and Francis & 1967 & Eros $(1926-65) 7$ parameters \\
\hline $20+$ & 328900 & \pm 60 & Ash et al. & 1967 & $\begin{array}{l}\text { Radar data }(1959-66) \\
\text { Optical data }(1950-65)\end{array}$ \\
\hline 21 & 328900 & 1.5 & Sjogren et al. & 1967 & Ranger lunar probes \\
\hline $22+$ & 328894 & $\pm \quad 30$ & Schubart and Zech & 1967 & Eros $(1926-65)$ \\
\hline $23 *$ & 328927 & \pm 50 & Schubart & 1969 & Amor (1932-64) \\
\hline $24+$ & 328915 & \pm & Lieske & 1968 & Eros (1893-1966) \\
\hline 25 & 328900.1 & 0.4 & $\begin{array}{l}\text { Anderson (see } \\
\text { Melbourne } \text { et al., } \\
\text { 1968) }\end{array}$ & 1968 & Ranger data \\
\hline $26+$ & 328899.86 & 2.04 & Sjogren et al. & 1966 & Ranger 3 (Jan. 62) \\
\hline $27-t$ & 328899.67 & \pm 10.85 & Sjogren et al. & 1966 & Ranger 4 (April 62) \\
\hline $28+$ & 328901.84 & \pm 10.76 & Sjogren et al. & 1966 & Ranger 5 (Oct. 62) \\
\hline $29+$ & 328900.61 & 1.87 & Sjogren et al. & 1966 & Ranger 6 (Jan. 64) \\
\hline $30+$ & 328899.89 & 1.35 & Sjogren et al. & 1966 & Ranger 7 (July 64) \\
\hline $31+$ & 328900.27 & 0.67 & Sjogren et al. & 1966 & Ranger 8 (Feb. 65) \\
\hline $32+$ & 328899.96 & 0.73 & Sjogren et al. & 1966 & Ranger 9 (Mar. 65) \\
\hline $33+$ & 328900.15 & 0.85 & Wong & 1968 & Surveyor 1 (May 66) \\
\hline $34+$ & 328900.29 & 0.86 & Wong & 1968 & Surveyor 3 (Apr. 67) \\
\hline $35+$ & 328900.23 & 1.02 & Wong & 1968 & Surveyor 4 (July 67 ) \\
\hline $36+$ & 328900.30 & 0.68 & Wong & 1968 & Surveyor 5 (Sept. 67) \\
\hline $37+$ & 328900.30 & 0.60 & Wong & 1968 & Surveyor 6 (Nov. 67) \\
\hline $38+$ & 328900.30 & 0.84 & Wong & 1968 & Surveyor 7 (Jan. 68) \\
\hline $39 *$ & 328900.46 & 1.87 & $\begin{array}{l}\text { Mottinger and } \\
\text { Sjogren }\end{array}$ & 1967 & Lunar Orbiter 2 (Nov. 66) \\
\hline $40+$ & 328899.70 & 1.14 & Anderson & 1967 & Mariner 4 (Nov. 64) \\
\hline & 328899.98 & 0.33 & Anderson and Hilt & 1968 & Mariner 5 (Jun. 67) \\
\hline \multirow[t]{3}{*}{$42 *$} & 328899.68 & 1.47 & Anderson and Hilt & 1968 & Pioneer 7 (Aug. 66) \\
\hline & 329390 & & Currently adopted & & \\
\hline & 328900.12 & $\pm \quad 0.20$ & Weighted mean & & \\
\hline
\end{tabular}


it is believed to be more determinate. It is recognized that the three analyses contain some common observational data. Due to the greater extent of his observations, Lieske's determination was given a weight of two, while the other determinations received a weight of one. The resulting group mean was $328906 \pm 7$, where the mean error is based on the discordance among the determinations.

(b) The mass determined from radar range measurements by Muhleman (1965) and Ash et al. (1967), which supersede Kotelnikov et al. (1962), were combined with equal weight to give a group mean of $328901.6 \pm 42.4$. The mean error is based on the published mean errors of the independent determinations.

(c) Schubart (1969) derived the reciprocal mass of the Earth-Moon from the perturbations induced in the minor planet Amor and this value was adopted.

(d) Since there is a possibility of systematic effects in results derived from different types of spacecraft due to differing instrumentation and measuring techniques, spacecraft determinations have been considered separately. The values based on the orbits of the Ranger spacecraft give a weighted group mean of $328900.12 \pm 0.44$, where the mean error is based on the mean errors of the independent determinations.

(e) Based on the Surveyor spacecraft series, the weighted group mean is $328900.27 \pm$ \pm 0.32 where the mean error is based on the errors of the independent determinations.

(f) The values from the Mariner spacecraft data give a weighted group mean of $328899.96 \pm 0.32$ with the mean error based on the uncertainty of the determinations.

(g) The Lunar Orbiter result was adopted.

(h) The Pioneer 5 determination (1960) was discarded because of the presence of systematic errors, and the determination from Pioneer 7 (1968) was adopted.

The values based on solar parallax and comet determinations were omitted from the solution because of the suspected presence of systematic errors. The group means were weighted $51,1.4,1,12913,24414,24414,715$, and 1157 , respectively, giving the final mean value of $328900.12 \pm 0.20$. The mean error is based on the accuracies of the group means rather than their discordance.

\section{Mars, Table IV}

(a) For the reciprocal mass of Mars derived from the motion of the satellites, Wilkins' (1966) analyses based on both satellites was selected since it includes more data than the determination based on Deimos alone. This supersedes prior determinations.

(b) The values derived by Anderson et al. (1970) from doppler observations of Mariners 4 and 6 were combined to give a weighted group mean of $3098709 \pm 9$ where the mean error is based on the given mean error of the determinations. The determination by Anderson (Himmel, 1969) from Mariner 6 data is superseded by the later analysis of Anderson et al. (1970).

(c) For the mass derived from planetary perturbations deduced from radar range measurements of the planet the determination of Anderson et al. (1970) was not used 
TABLE IV

Investigations of the mass of Mars

\begin{tabular}{|c|c|c|c|c|c|}
\hline No. & $\begin{array}{l}\text { Reciprocal } \\
\text { mass }\end{array}$ & Mean error & Author & Year & Object \\
\hline 1 & 3093500 & \pm 5000 & Hall & 1878 & Satellites \\
\hline 2 & 3088000 & \pm 7400 & van den Bosch & 1927 & Satellites $(1877-1909)$ \\
\hline 3 & 3110000 & \pm 11400 & Rabe & 1950 & Eros $(1926-45)$ \\
\hline 4 & 3079000 & \pm 8500 & Urey & 1952 & Deimos \\
\hline $5 *$ & 3096000 & \pm 6000 & Wilkins & 1966 & Satellites $(1877-1928)$ \\
\hline 6 & 3094000 & \pm 4000 & Wilkins & 1966 & Deimos $(1877-1928)$ \\
\hline $7 *$ & 3111000 & \pm 9000 & Ash et al. & 1967 & $\begin{array}{l}\text { Radar data (1959-66) } \\
\text { Optical data }(1950-65)\end{array}$ \\
\hline 8 & 3098600 & $\pm \quad 890$ & Null et al. & 1967 & Mariner 4 \\
\hline 9 & 3098700 & $\pm \quad 148$ & $\begin{array}{l}\text { Null (see Melbourne } \\
\text { et al., 1968) }\end{array}$ & 1968 & Mariner 4 \\
\hline 10 & 3098700 & $\pm \quad 148$ & $\begin{array}{l}\text { Anderson (see } \\
\text { Himmel) }\end{array}$ & 1969 & Mariner 6 \\
\hline 11 & 3098697 & \pm 100 & Anderson et al. & 1970 & Mariner 6 Radar data of Mars \\
\hline $12+$ & 3098716 & $\pm \quad 132$ & Anderson et al. & 1970 & Mariner 6 \\
\hline $13+$ & $\begin{array}{l}3098709 \\
3093500 \\
3098709\end{array}$ & $\begin{array}{l} \pm \\
\pm\end{array}$ & $\begin{array}{l}\text { Anderson } e t \text { al. } \\
\text { Currently adopted } \\
\text { Weighted mean }\end{array}$ & 1970 & Mariner 4 \\
\hline
\end{tabular}

since it is primarily dependent upon the Mariner 6 data. The determination by Ash et al. (1967) was adopted.

The group means were given weights of 2,1000000 , and 1 , respectively in forming the weighted mean of $3098709 \pm 9$ where the mean error is determined from the accuracy of the group means.

\section{Jupiter, Table V}

(a) In forming the group mean for the mass of Jupiter derived from its effects on the motion of minor planets, the determinations by Encke (1826), Powalky (1864), Hansen and Krueger (1873) and Newcomb (1894) were omitted from consideration since there are more recent determinations which incorporate the same observational material. A weighted mean of the 18 remaining determinations was formed. In those cases where no weight was given by the investigator a weight of unity was arbitrarily assigned. The resulting weighted mean of $1047.366 \pm 0.005$ for the reciprocal mass of Jupiter is thought to be representative of the modern determinations. The mean error was determined by the discordances of the individual values from the weighted mean.

(b) The determinations of Jupiter's mass from satellite observations made by Newton (1686), Lagrange (1782), Laplace (1802) and Schur-Triesnecker (1882) are not considered since they rest solely on observations made before 1800 and therefore can not contribute significantly to the final result. The investigations of Santini (1835), Airy (1837), Bessel (1841), Vogel (1880) and Kulikov (1950) are superseded and have 
TABLE $V$

Investigations of the mass of Jupiter

$\begin{array}{llll}\text { No. Reciprocal Mean error Author } & \text { Year Object } \\ \text { mass }\end{array}$

\begin{tabular}{|c|c|c|c|c|c|}
\hline $1+$ & 1053.924 & & Nicolai & 1826 & (3) Juno \\
\hline 2 & 1053.36 & & Encke & 1826 & (4) Vesta \\
\hline $3+$ & 1048.69 & & Encke & 1837 & (2) Pallas \\
\hline 4 & 1047.88 & & Powalky & 1864 & (48) Doris \\
\hline $5+$ & 1048.23 & & Schubert & 1866 & (23) Thalia \\
\hline 6 & 1051.12 & \pm 1.2 & $\begin{array}{l}\text { Hansen } \\
\text { (see Kempf, 1882) }\end{array}$ & & (13) Egeria \\
\hline $7+$ & 1047.37 & \pm 1.538 & Becker & 1872 & (29) Amphitrite \\
\hline 8 & 1047.538 & \pm 0.285 & Krueger & 1873 & (24) Themis \\
\hline $9+$ & 1045.25 & \pm 0.68 & $\begin{array}{l}\text { Dubjago } \\
\text { (see Kempf, 1882) }\end{array}$ & & (78) Diana \\
\hline $10+$ & 1048.42 & & Bryant & 1889 & (80) Sappho \\
\hline 11 & 1047.34 & \pm 0.044 & Newcomb & 1894 & (33) Polyhymnia \\
\hline $12+$ & 1045.63 & & Leveau & 1896 & (4) Vesta \\
\hline $13 *$ & 1047.378 & \pm 0.179 & Hill & 1898 & Saturn \\
\hline $14+$ & 1047.558 & \pm 0.40 & Samter & 1910 & (13) Egeria (1850-1906) \\
\hline $15+$ & 1047.57 & \pm 0.095 & Osten & 1928 & (447) Valentine (1899-1918) \\
\hline $16+$ & 1047.387 & \pm 0.004 & O’Handley & 1967 & (65) Cybele \\
\hline $17+$ & 1047.356 & \pm 0.004 & Fiala & 1968 & (57) Mnemosyne (1859-1965) \\
\hline $18+$ & 1047.340 & \pm 0.024 & Zielenbach & 1968 & (48) Doris \\
\hline $19+$ & 1047.351 & \pm 0.006 & Klepczynski & 1969 & (10) Hygeia (1849-1966) \\
\hline $20+$ & 1047.359 & \pm 0.010 & Klepczynski & 1969 & (24) Themis (1853-1964) \\
\hline $21+$ & 1047.372 & \pm 0.006 & Klepczynski & 1969 & (31) Euphrosyne (1854-1964) \\
\hline $22+$ & 1047.337 & \pm 0.027 & Klepczynski & 1969 & (52) Europa (1858-1964) \\
\hline $23+$ & 1047.341 & \pm 0.011 & Janiczek & 1969 & (33) Polyhymnia (1854-1969) \\
\hline $24+$ & 1047.340 & \pm 0.013 & Doggett & 1969 & (49) Pales (1857-1968) \\
\hline 25 & 1067 & & Newton & 1686 & Satellite 4 \\
\hline 26 & 1067.195 & & Lagrange & 1782 & Satellite 4 \\
\hline 27 & 1067.09 & & Laplace & 1802 & Satellite 4 \\
\hline 28 & 1050.2 & \pm 2.5 & Santini & 1835 & Satellite 4 \\
\hline 29 & 1046.77 & & Airy & 1837 & Satellites 1-4 (1833-37) \\
\hline 30 & 1047.879 & \pm 0.348 & $\begin{array}{l}\text { Bessel } \\
\text { (see Schur, 1882) }\end{array}$ & 1841 & Satellites 1-4 (1834-39) \\
\hline 31 & 1047.760 & \pm 0.550 & $\begin{array}{l}\text { Vogel } \\
\text { (see Kempf, 1882) }\end{array}$ & 1880 & Satellites $3,4(1868-70)$ \\
\hline $32+$ & 1047.232 & \pm 0.365 & Schur & 1882 & Satellites 1-4 (1874-80) \\
\hline 33 & 1048.55 & \pm 2.15 & Schur-Triesnecker & 1882 & Satellites $1-4$ (1794-95) \\
\hline $34+$ & 1047.805 & \pm 1.11 & Schur-Airy & 1882 & Satellites 1-4 (1833-37) \\
\hline $35+$ & 1051.088 & \pm 2.242 & Schur-Santini & 1882 & Satellite 4 \\
\hline $36+$ & 1047.905 & \pm 0.199 & Schur-Bessel & 1882 & Satellites 1-4 (1834-39) \\
\hline $37+$ & 1047.54 & & Schur-Jacob & 1882 & Satellites 3-4 (1860) \\
\hline $38+$ & 1047.37 & \pm 1.20 & Kempf-Jacob & 1882 & Satellites 3-4 (1860) \\
\hline $39+$ & 1047.767 & \pm 0.460 & Kempf-Vogel & 1882 & Satellites 3-4 (1868-70) \\
\hline $40+$ & 1047.641 & \pm 0.724 & Kempf-Airy & 1882 & Satellites $1-4$ (1833-37) \\
\hline $41+$ & 1047.439 & \pm 0.138 & Cookson & 1906 & Satellites 1-4 (1901) \\
\hline $42+$ & 1047.247 & \pm 0.087 & Cookson & 1906 & Satellites 1-4 (1902) \\
\hline $43+$ & 1047.498 & \pm 0.086 & de Sitter & 1915 & Satellites 1-4 (1891) \\
\hline 44 & 1047.411 & \pm 0.6 & Kulikov & 1950 & Satellite $8(1930-46)$ \\
\hline $45+$ & 1047.335 & \pm 0.077 & Herget & 1968 & Satellite $8(1908-65)$ \\
\hline $46+$ & 1047.386 & $\pm \mathbf{0 . 0 6 1}$ & $\mathrm{Bec}$ & 1969 & Satellite $9(1914-68)$ \\
\hline
\end{tabular}


Table V (Continued)

\begin{tabular}{|c|c|c|c|c|c|}
\hline No. & $\begin{array}{l}\text { Reciprocal } \\
\text { mass }\end{array}$ & Mean error & Author & Year & Object \\
\hline $\begin{array}{l}47+ \\
48+\end{array}$ & $\begin{array}{l}1047.788 \\
1050.478\end{array}$ & \pm 0.408 & $\begin{array}{l}\text { Möller } \\
\text { Von Asten } \\
\text { (see von Haerdtl, } 1\end{array}$ & $\begin{array}{l}1872 \\
89)\end{array}$ & $\begin{array}{l}\text { Faye's comet } \\
\text { Encke's comet }\end{array}$ \\
\hline $\begin{array}{l}49+ \\
50+ \\
51+\end{array}$ & $\begin{array}{l}1047.175 \\
1050.93 \\
1050.99 \\
1047.355 \\
1047.366\end{array}$ & $\begin{array}{l} \pm 0.014 \\
\pm 0.33 \\
\pm 0.98 \\
\pm 0.007\end{array}$ & $\begin{array}{l}\text { von Haerdtl } \\
\text { Rasmussen } \\
\text { Rasmussen } \\
\text { Currently adopted } \\
\text { Weighted mean }\end{array}$ & $\begin{array}{l}1889 \\
1967 \\
1967\end{array}$ & $\begin{array}{l}\text { Winnecke's comet }(1858-86) \\
\text { Olber's comet }(1815,1887,1955) \\
\text { Halley's comet }(1759,1835,1910)\end{array}$ \\
\hline
\end{tabular}

been omitted. A weighted mean of the 13 remaining investigations gives $1047.394 \pm$ \pm 0.040 where the mean error is derived from the discordance of the individual values.

(c) The five determinations based on analyses of the motion of comets were combined to yield a weighted mean of $1047.184 \pm 0.089$. This result is strongly influenced by the large weight given to the determination by von Haerdtl (1889) due to its unrealistic mean error. The mean error of the weighted mean was derived from the mutual discordances with respect to the weighted mean.

(d) Hill's determination of the mass of Jupiter from its influence on the motion of Saturn was adopted.

The resulting mass of Jupiter reflects the small mean error associated with the mass as determined from minor planet studies. In forming the mean value, relative weights of $1282,20,4$, and 1 were assigned to the four group means. The resulting weighted mean along with its mean error determined by discordances with respect to the mean is $1047.366 \pm 0.007$.

The authors feel that the true value probably lies within a range of five times the mean error on either side of the mean, i.e., between 1047.331 and 1047.401.

\section{Saturn, Table VI}

(a) Since van den Bosch (1927) includes the work of Bessel (1833) in his investigation, the latter is not considered further. The investigations of van den Bosch (1927), Woltjer (1928) and Jeffreys (1954) which utilized observations of the satellites to determine a value for the mass of Saturn were combined with weights 1.0, 1.2, and 7, respectively, to yield a weighted mean of $3494.12 \pm 1.45$. Since the three values happen to be in close agreement, it was felt that determining the mean error by the discordances with respect to the mean would not truly reflect the accuracy of the result. Rather, the mean error of the mean was obtained by dividing the mean error of unit weight by the square root of the sum of the weights.

(b) The analysis of the mass of Saturn by Hill (1898) from its effect on the motion of 
Jupiter is superseded by Gaillot (1913). Forming a weighted mean of the determination by Gaillot (1913), Hertz (1953) and Klepczynski et al. (1970), the value $3498.5 \pm 0.3$ was obtained as the group mean. Here, the mean error was derived from the discordances with respect to the mean.

(c) The investigation by Clemence (1960), since it analyzed only the secular perturbations of Saturn on Jupiter, was considered independent of those investigations which utilized periodic perturbations and was adopted.

(d) Marsden's (1970) analysis using the motion of the minor planet Hidalgo is the only such determination and is adopted.

(e) Similarly, the use of the comet P/Schwassmann-Wachmann 1 by Herget (1970) is the only such analysis and it is adopted.

The five group means were combined with weights $1,23,6,23,53$ and the resulting weighted mean is $3498.1 \pm 0.4$. The mean error was determined by the mutual discordances with respect to the mean.

TABLE VI

Investigations of the mass of Saturn

\begin{tabular}{clllll}
\hline No. & $\begin{array}{l}\text { Reciprocal } \\
\text { mass }\end{array}$ & $\begin{array}{l}\text { Mean } \\
\text { error }\end{array}$ & Author & Year & Object \\
\hline & & & & & \\
1 & 3501.6 & \pm 1.15 & Bessel & 1833 & Titan \\
2 & 3502.2 & \pm 0.79 & Hill & 1898 & Jupiter (1750-1888) \\
$3+$ & 3499.8 & \pm 1.75 & Gaillot & 1913 & Jupiter (1750-1907) \\
$4+$ & 3496 & \pm 4.4 & van den Bosch & 1927 & Satellites (1830-1915) \\
$5+$ & 3493 & \pm 4 & Woltjer & 1928 & Hyperion \\
$6+$ & 3497.64 & \pm 0.40 & Hertz & 1953 & Jupiter (1884-1948) \\
$7+$ & 3494.04 & \pm 1.65 & Jeffreys & 1954 & Satellites (1924-37) \\
$8 *$ & 3499.7 & \pm 0.6 & Clemence & 1960 & Secular perturbations \\
& & & & & Jupiter (1779-1941) \\
$9 *$ & 3498.5 & \pm 0.30 & Marsden & 1970 & Hidalgo (1920-64) \\
$10 *$ & 3497.6 & \pm 0.20 & Herget & 1970 & Comet P/Schwassmann- \\
& & & & Wachmann 1 (1927-65) \\
$11+$ & 3498.7 & \pm 0.2 & Klepczynski et al. & 1970 & Jupiter (1913-68) \\
& 3501.6 & & Currently adopted & & \\
& 3498.1 & \pm 0.4 & Weighted mean & & \\
\hline
\end{tabular}

\section{Uranus, Table VII}

(a) There are two investigations which analyze the perturbations of Uranus on Saturn to derive its mass. The investigation by Hill (1898) depends on Hill's theory of Saturn which is known to have errors (Clemence, 1951). For this reason, Hill's value is eliminated from consideration, and the determination by Klepczynski et al. (1970) is adopted.

(b) The value of 22530 given by van den Bosch (1927), obtained from observations of the satellites, is dropped from consideration because it includes observations which are thought to be affected by systematic errors. These observations are not included 
TABLE VII

Investigations of the mass of Uranus

\begin{tabular}{llllll}
\hline No. & $\begin{array}{l}\text { Reciprocal } \\
\text { mass }\end{array}$ & $\begin{array}{l}\text { Mean } \\
\text { error }\end{array}$ & Author & Year & Object \\
\hline 1 & 23239 & \pm 132 & Hill & 1898 & Saturn (1751-1888) \\
$2+$ & 22685 & \pm 31 & van den Bosch & 1927 & Oberon (1874-1911) \\
$3+$ & 22831 & \pm 25 & van den Bosch & 1927 & Titania (1874-1911) \\
$4+$ & 22919 & \pm 255 & van den Bosch & 1927 & Umbriel (1874-1901) \\
$5+$ & 23073 & \pm 144 & van den Bosch & 1927 & Ariel (1874-1901) \\
6 & 22530 & \pm 74 & van den Bosch & 1927 & Satellites (1874-1911) \\
$7+$ & 22934 & \pm 9 & Harris & 1950 & Satellites (photographic) \\
$8 *$ & 22692 & \pm 33 & Klepczynski et al. & 1970 & Saturn (1913-68) \\
& 22869 & & Currently adopted & & \\
& 22800 & \pm 107 & Weighted mean & & \\
\hline
\end{tabular}

in the determinations from individual satellites. The remaining five determinations of the mass of Uranus which used observations of the satellites were combined to yield a weighted mean of $22906 \pm 34$. The mean error is based on the discordance among the values.

The mean value obtained by combining these two group means is $22800 \pm 107$. The value and the mean error reflect the two discordant values which received equal weight in forming the mean.

\section{Neptune, Table VIII}

(a) The determination of the mass of Neptune by investigating its effects on the motion

TABLE VIII

Investigations of the mass of Neptune

\begin{tabular}{|c|c|c|c|c|c|}
\hline No. & $\begin{array}{l}\text { Reciprocal } \\
\text { mass }\end{array}$ & $\begin{array}{l}\text { Mean } \\
\text { error }\end{array}$ & Author & Year & Object \\
\hline $\begin{array}{l}1 \\
2\end{array}$ & $\begin{array}{l}19700 \\
19314\end{array}$ & \pm 200 & $\begin{array}{l}\text { Newcomb } \\
\text { Newcomb }\end{array}$ & $\begin{array}{l}1874 \\
1898 \mathrm{~b}\end{array}$ & $\begin{array}{l}\text { Uranus (1690-1872) } \\
\text { Uranus (1781-1896) } \\
\text { Triton }\end{array}$ \\
\hline 3 & 19094 & \pm 33 & Gaillot & 1910 & Uranus (1690-1903) \\
\hline 4 & 19176 & +37 & $\begin{array}{l}\text { Eichelberger and } \\
\text { Newton }\end{array}$ & 1926 & Triton visual \\
\hline 5 & 19655 & \pm 53 & $\begin{array}{l}\text { Eichelberger and } \\
\text { Newton }\end{array}$ & 1926 & Triton photographic \\
\hline 6 & 19331 & \pm 31 & $\begin{array}{l}\text { Eichelberger and } \\
\text { Newton }\end{array}$ & 1926 & Triton combined \\
\hline 7 & 18889 & \pm 92 & van Biesbroeck & 1957 & Nereid (1949-55) \\
\hline $8 *$ & 19296 & \pm 31 & Gill and Gault & 1968 & Triton (1887-1958) \\
\hline 9* & $\begin{array}{l}19349 \\
19314 \\
19325\end{array}$ & $\begin{array}{l} \pm 28 \\
\pm 26\end{array}$ & $\begin{array}{l}\text { Seidelmann } \text { et al. } \\
\text { Currently adopted } \\
\text { Weighted mean }\end{array}$ & 1969 & Uranus (1781-1968) \\
\hline
\end{tabular}


of Uranus obtained by Seidelmann et al. (1969) supersedes the analyses of Newcomb $(1874,1898 \mathrm{~b})$ and Gaillot (1910) and is adopted.

(b) Of the determinations of the mass of Neptune from the motion of its satellites, we adopt the value of Gill and Gault (1968) since it supersedes the investigation of Eichelberger and Newton (1926). However, the mean error of Eichelberger and Newton is assigned to the determination of Gill and Gault, since $83 \%$ of the observational material is in common and the accuracy of the added observations appears comparable to that used earlier. Due to correlations existing among the unknowns, which may systematically affect the results, it was decided to not include the determination by by Van Biesbroeck (1957) in this discussion.

The two group means are in fairly good agreement and each contributes almost equally to the weighted mean of $19325 \pm 26$. The mean error was determined from the mutual discordances with respect to the mean.

\section{Pluto, Table IX}

(a) The previous gravitational determinations are superseded by investigation 10 . Item 2 is omitted since it is derived only from brightness measures. The value $1812000 \pm 50000$ is therefore adopted as the provisional mass of Pluto; the error has been estimated rather than derived formally.

TABLE IX

Investigations of the mass of Pluto

\begin{tabular}{|c|c|c|c|c|c|}
\hline No. & $\begin{array}{l}\text { Reciprocal } \\
\text { mass }\end{array}$ & $\begin{array}{l}\text { Mean } \\
\text { error }\end{array}$ & Author & Year & Object \\
\hline 1 & $>330000$ & & Jackson & 1930 & Neptune (1795-1928) \\
\hline 2 & 3000000 & & Bower & 1931 & Brightness \\
\hline 3 & 350000 & \pm 90000 & $\begin{array}{l}\text { Nicholson and } \\
\text { Mayall }\end{array}$ & 1931 & Neptune (1795-1930) \\
\hline 4 & $>660000$ & & Brown & 1931 & Uranus $(1780-1900)$ \\
\hline 5 & 330000 & \pm 46500 & Wylie & 1942 & Neptune (1795-1938) \\
\hline 6 & 350000 & \pm 50000 & Kourganoff & 1944 & Neptune \\
\hline 7 & 930000 & \pm 726000 & Eckert et al. & 1951 & Uranus (1781-1938) \\
\hline 8 & 400000 & \pm 59000 & Brouwer & 1955 & $\begin{array}{l}\text { Uranus and Neptune } \\
(1712-1941)\end{array}$ \\
\hline 9 & 450000 & \pm 118000 & Brouwer & 1955 & $\begin{array}{l}\text { Longitudes of Uranus and } \\
\text { Neptune (1712-1941) }\end{array}$ \\
\hline $10 *$ & $\begin{array}{r}1812000 \\
360000 \\
1812000\end{array}$ & $\begin{array}{l} \pm 50000 \\
\pm 50000\end{array}$ & $\begin{array}{l}\text { Duncombe } e t \text { al. } \\
\text { Currently adopted } \\
\text { Recommended value }\end{array}$ & 1968 & Neptune (1795-1968) \\
\hline
\end{tabular}

\section{Summary}

The final set of masses is exhibited in Table $\mathrm{X}$ along with some previous determinations. 
THE MASSES OF THE PRINCIPAL PLANETS

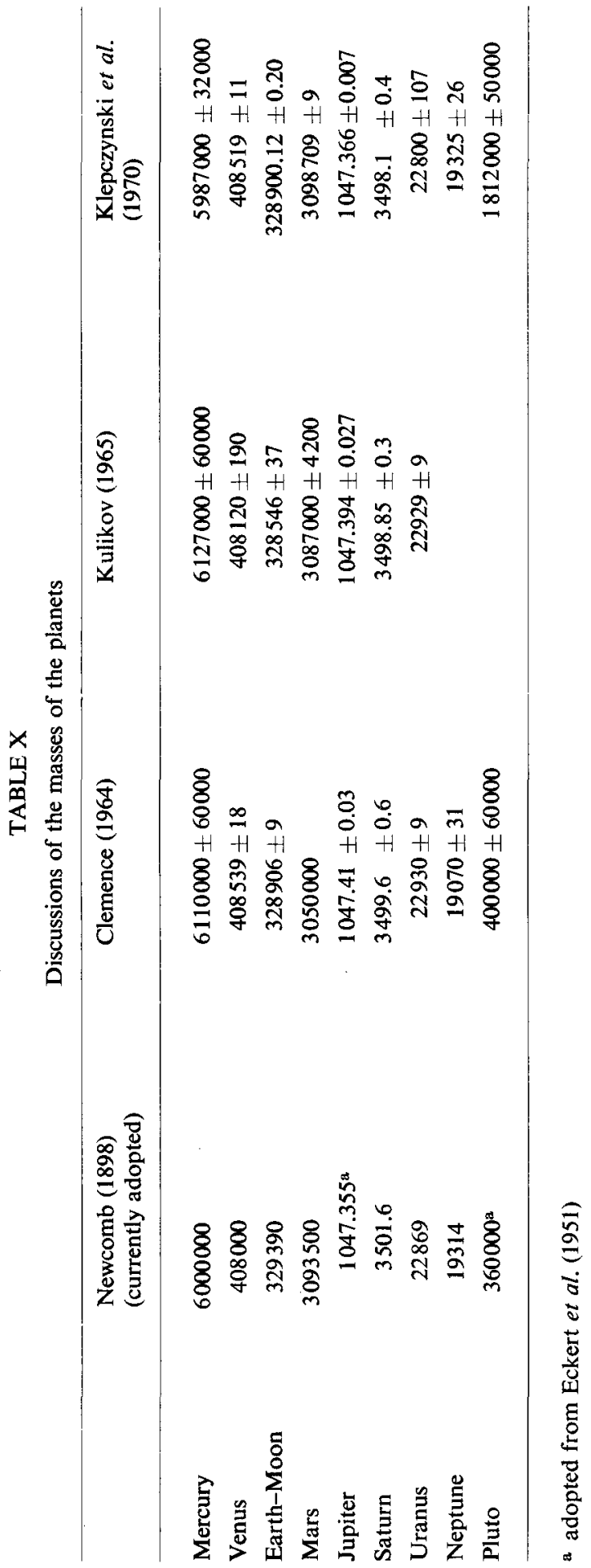




\section{References}

(Combined list of references to both this paper and J. Kovalevsky, 'Détermination des Masses des Planètes', pp. 213-223).

Airy, G. B.: 1833-37, Mem. Roy. Astron. Soc. 6, 83; 8, 33; 9, 7; 10, 43.

Anderson, J. D.: 1964, AIAA Proceedings (ed. by Szebehely).

Anderson, J. D.: 1967, Dissertation, UCLA.

Anderson, J. D.: 1967, Jet Propul. Lab. Tech. Rep. No. 32-816.

Anderson, J. D. and Efron, L.: 1969, Bull. AAS 1, 231.

Anderson, J. D. and Hilt, D. E.: 1968, Am. Astron. Soc. Pap. 68-130.

Anderson, J. D., Efron, L., and Pease, G. E.: 1968, Astron. J. Suppl. 73, S-162.

Anderson, J. D., Efron, L., and Wong, S. K.: 1970, Science 167, 277.

Anderson, J. D., Null, G. W., and Thornton, C. T.: 1964, 'Celestial Mechanics and Astrodynamics', in Progress in Aeronautics and Astronics Series 14, Academic Press, New York, p. 131.

Anderson, J. D., Esposito, P. B., Martin, W., and Muhleman, D. O.: 1970, Communication à la 13e Assemblée Generale du COSPAR, Léningrad, Mai 1970.

Ash, M. E., Shapiro, I. I., and Smith, W. B.: 1967, Astron. J. 72, 338.

Backlund, M. O.: 1894, Bull. Astron. 11, 473.

Bec, A.: 1969, Astron. Astrophys. 2, 381.

Becker, E.: 1872, Publ. Astron. Gesellsch. Nr. 10.

Bessel, F. W.: 1833, Astron. Nachr. 11, 17.

Böhme, S. and Fricke, W.: 1965, Bull. Astron. 25, 280.

Bower, E. C.: 1931, Lick Obs. Bull. XV, No. 437.

Brouwer, D.: 1950, Bull. Astron. 15, 171.

Brouwer, D.: 1955, Monthly Notices Roy. Astron. Soc. 115, 221.

Brouwer, D. and Clemence, G.: 1961, 'Orbits and Masses of Planets and Satellites' in The Solar System (ed. by Kuiper and Middlehurst), 3.

Brown, E. W.: 1931, Monthly Notices Roy. Astron. Soc. 92, 80-101.

Bryant, R.: 1889, Astron. Nachr. 121, 231.

Clemence, G. M.: 1943, Astron. Papers Am. Ephem. 11, pt. 1.

Clemence, G. M.: 1949, Proc. Am. Phil. Soc. 93, 532.

Clemence, G. M.: 1960, Astron. J. 65, 21.

Clemence, G. M.: 1961, in Planets and Satellites (ed. by Kuiper and Middlehurst), University of Chicago Press, p. 61.

Clemence, G. M.: 1966, in 'Proceedings of the 12th General Assembly 1964', IAU Transactions 12B, 610.

Cookson, B.: 1906, Ann. Cape Obs. 12, pt. II.

Cowell, P. H.: 1906, Monthly Notices Roy. Astron. Soc. 66, 302.

de Sitter, W.: 1915, Ann. Cape Obs. 12, pt. I.

Doggett, L. E.: 1969, Thesis, Georgetown Univ.

Duncombe, R. L.: 1958, Astron. Papers Am. Ephem. 16, pt. 1.

Duncombe, R. L.: 1965, Bull. Astron. 25, 137.

Duncombe, R. L., Klepczynski, W. J., and Seidelmann, P. K.: 1968, Astron. J. 73, 830.

Eckert, W. J., Brouwer, D., and Clemence, G. M.: 1951, Astron. Papers Am. Ephem. 12.

Eichelberger, W. S. and Newton, A.: 1926, Astron. Papers Am. Ephem. 9, pt. 3.

Encke, J. F.: 1826, Abh. Berliner Akad. Wiss., 267.

Encke, J. F.: 1837, Astron. Nachr. 14, 331.

Fiala, A. D.: 1969, Bull. AAS 1, 342.

Fotheringham, J. K.: 1935, Astron. Nachr. 256, 6121.

Gaillot, M. A.: 1910, Ann. Obs. Paris 28, A 1.

Gaillot, M. A.: 1913, Ann. Obs. Paris 31, 105.

Gill, J. R. and Gault, B. L.: 1968, Astron. J. 73, S 95.

Hall, A.: 1878, Observations and Orbits of the Satellites of Mars with Data for Ephemeris in 1879, Washington, Government Printing Office.

Halliday, I., Hardie, R. H., Franz, O., and Priser, J. B.: 1965, Astron. J. 70, 676.

Harris, D.: 1950, Dissertation, University of Chicago. 
Herget, P.: 1968, Astron. J. 73, 737.

Herget, P. and Carr, H. J.: 1970, Bull. AAS 2, 245.

Hertz, H. G.: 1953, Astron. Papers Am. Ephem. 15, pt. 2.

Hertz, H. G.: 1966, Circul. Bur. Centr. Télegr. Astron. No. 1983.

Hill, G. W.: 1898, Astron. Papers Am. Ephem. 7, 160.

Himmel, N.: 1969, Aviation Week 91, 95.

Hinks, A.: 1909, Monthly Notices Roy. Astron. Soc. 69, 544.

Hinks, A.: 1910, Monthly Notices Roy. Astron. Soc. 70, 588.

Jackson, J.: 1930, Monthly Notices Roy. Astron. Soc. 90, 728-32.

Janiczek, P.: 1969, Dissertation, Georgetown Univ.

Jeffreys, H.: 1954, Monthly Notices Roy. Astron. Soc. 114, 433.

Jones, H. S.: 1925, Monthly Notices Roy. Astron. Soc. 85, 853.

Jones, H. S.: 1926, Monthly Notices Roy. Astron. Soc. 86, 426.

Jones, H. S.: 1927, Monthly Notices Roy. Astron. Soc. 87, 602.

Jones, H. S.: 1932, Ann. Cape Obs. 13, pt. 3.

Jones, H. S.: 1941, Mem. Roy. Astron. Soc. 66, pt. $2,11$.

Kempf, P.: 1882, Publ. Astrophys. Obs. Potsdam 3, pt. II, No. 10.

Kempf, P.: 1883, Astron. Nachr. 105, 325.

Klepczynski, W. J.: 1969, Astron. J. 74, 774.

Klepczynski, W. J., Seidelmann, P. K., and Duncombe, R. L.: 1970, Astron. J. 75, 739.

Kotelnikov, V. A. et al.: 1962, Dokl. Akad. Sci. U.S.S.R. 145, 5.

Kourganoff, V.: 1944, Ciel Terre 60.

Kovalevsky, J.: 1970, in Surfaces and Interiors of Planets and Satellites (ed. by Dollfus), Academic Press, p. I.

Kozlovskaya, S. V.: 1963, Bull. Inst. Astron. Théor. Léningrad 9, 330.

Krueger, A.: 1873, Astron. Nachr. 81, 331.

Kulikov, D. K.: 1950, Bull. Inst. Astron. Théor. Léningrad 4, 311.

Kulikov, D. K.: 1965, Bull. Astron. 25, 139-51.

Lagrange, J. L.: 1782, Mem. Berlin, p. 183.

Laplace, P. S.: 1802, Traité Mécanique Céleste 3, 62.

Leveau, G.: 1896, Ann. Obs. Paris 22, A 57.

Lieske, J. H.: 1968, Astron. J. 73, 628.

Lieske, J. H. and Null, G. W.: 1969, Astron. J. 74, 297.

Makover, S. G.: 1956, Publ. Inst. Astron. Théor. Léningrad No. 6, p. 67.

Makover, S. G. and Bokhan, N. A.: 1961, Trudy Inst. Astron. Théor. Léningrad 8, 135.

Marsden, B. G.: 1970, Astron. J. 75, 215.

Melbourne, W. J.: 1969, COSPAR Symp. C, Prague, Czechoslovakia.

Melbourne, W. J.: 1970, in Dynamics of Satellites (ed. by Morando), Springer Verlag, p. 63.

Melbourne, W. J. and O'Handley, D. A.: 1968, Jet Propul. Lab. Space Program Summary, 37-53, vol. III, p. 1.

Melbourne, W. J., Mulholland, J. D., Sjogren, W. L., and Sturm, F. M. Jr.: 1968, Jet. Propul. Lab. Tech. Rep. No. 32-1306.

Möller, A.: 1972, Viertelj. Astron. Gesellsch. 7, 85.

Morgan, H. R.: 1933, Astron. J. 42, 149.

Morgan, H. R. and Scott, F. P.: 1939, Astron. J. 47, 193.

Mottinger, N. A. and Sjogren, S. L.: 1967, JPL SPS 37-46, III, 19.

Muhleman, D. O.: 1965, Bull. Astron. 25, 153-175.

Mulholland, J. D.: 1967, Jet. Propul. Lab. Space Program Summary, 37-45, vol. IV, p. 17.

Mulholland, J. D.: 1968, Astron. J. 73, S-28.

Newcomb, S.: 1874, Smithsonian Contrib. Knowl. 19, 173-7.

Newcomb, S.: 1894, Astron. Nachr. 136, 129.

Newcomb, S.: 1895a, Astron. Papers Am. Ephem. 5, 381-449.

Newcomb, S.: 1895b, Supplement to the American Ephemeris and Nautical Almanac for 1897, p. 1-202.

Newcomb, S.: 1898a, Astron. Papers Am. Ephem. 6.

Newcomb, S.: 1898b, Astron. Papers Am. Ephem. 7.

Newton, I.: 1686, Principia, Book III, Prop. 8.

Nicholson, S. B. and Mayall, N. U.: 1931, Astrophys. J. 73, 1-12. 
Nicolai, F.: 1826, Berliner Astron. Jahrbuch, p. 227.

Noteboom, E.: 1921, Astron. Nachr. 214, 154.

Null, G. W.: 1969, Bull. AAS 1, 356.

Null, G. W. and Lieske, J. M.: 1969, Bull. AAS 1, 198.

Null, G. W., Gordon, H. J., and Tito, A. D.: 1967, JPL Tech. Rep. 32-1108.

O'Handley, D. A.: 1967, Dissertation, Yale Univ.

O'Handley, D. A.: 1968, Astron. J. 73, S-29.

Osten, M.: 1928, Astron. Nachr. 232, 225.

Powalky, C.: 1864, Astron. Nachr. 62, 321.

Rabe, E.: 1950, Astron. J. 55, 112.

Rabe, E.: 1954, Astron. J. 59, 409.

Rabe, E.: 1967, Astron. J. 72, 852.

Rabe, E. and Francis, M. P.: 1967, Astron. J. 72, 856.

Rasmussen, H. Q.: 1967, Publ. Copenhagen Obs. Nr. 194.

Ross, F. E.: 1917, Astron. Papers Am. Ephem. 9, p. 261.

Samter, H.: 1910, Astron. Abhandl. Erg. Z. Astron. Nachr. 3, No. 17, 9.

Santini, G.: 1835, Astron. Nachr. 12, 285.

Scholl, H.: 1971, Celes. Mech. 4, 250.

Schubart, J.: 1969, Astron. Astrophys, 2, 173.

Schubart, J.: 1970, Circul. Bur. Centr. Télegr. Astron., No. 2268.

Schubart, J. and Zech, G.: 1967, Nature 214, 900.

Schubert, E.: 1866, Astron. Nachr. 66, 25.

Schur, W.: 1882, Astron. Nachr. 104, 81-6.

Seidelmann, P. K., Duncombe, R. L., and Klepczynski, W. J.: 1969, Astron. J. 74, 776.

Sjogren, W. L., Trask, D. W., Vegos, C. J., and Wollenhaupt, W. R.: 1966, JPL Tech. Rep. 32-1057.

Taylor, B. N., Parker, W. H., and Langenberg, D. N.: 1969, Rev. Mod. Phys. 41, 375.

Urey, H. C.: 1952, The Planets, New Haven.

Van Biesbroeck, G.: 1957, Astron. J. 62, 272.

Van den Bosch, C. A.: 1927, De Massa's van de Groote Planeten, G. Bakker, Baarn.

von Haerdtl, F.: 1889a, Denkschr. Kaiserl. Acad. Wiss. 56.

von Haerdtl, F.: 1889b, Astron. Nachr, 120, 257.

Wilkins, G. A.: 1967, in Mantles of the Earth and Terrestrial Planets (ed. by Runcorn,), Interscience

Publ., p. 77.

Williams, K. P.: 1939, Publ. Kirkwood Obs. Indiana Univ., No. 1.

Witt, G.: 1905, Doctoral dissertation, Berlin.

Witt, G.: 1908, Viertelj. Astron. Gesellsch. 43, 295.

Witt, G.: 1933, Astron. Abhandl. Erg. Z. Astron. Nachr. 9, No. 1.

Woltjer, J.: 1928, Ann. Leiden 16, 3.

Wong, S. K.: 1968, JPL SPS 37-52, II, p. 12.

Wylie, L. R.: 1942, Publ. U.S. Naval Obs., 2nd ser., 15, pt. 1.

Zech, G.: Veröffentl. Astron. Rechen-Inst. Heidelberg No. 21.

Zielenbach, J. W.: 1960, Sky and Telescope 20, 6, 337.

Zielenbach, J. W.: 1962, Astron. J. 67, 1299.

Zielenbach, J. W.: 1964, Transactions of IAU, 12A, 16.

Zielenbach, J. W.: 1968, Dissertation, Georgetown Univ.

Zielenbach, J. W.: 1969, Astron. J. 74, 567. 